\title{
Strategi Pengembangan Perdesaan Berbasis Tanaman Industri di Kabupaten Takalar, Provinsi Sulawesi Selatan
}

\author{
Industrial Crop Based Rural Development Strategy in Takalar Regency, \\ South Sulawesi Province
}

\author{
Muhammad Anshar $^{*}$ \& Zulkifli ${ }^{1}$ \\ ${ }^{1}$ Departemen Teknik Perencanaan Wilayah dan Kota, Fakultas Sains dan Teknologi, Universitas Islam \\ Negeri Alauddin Makassar, Jalan H.M. Yasin Limpo Nomor 63, Gowa, 92113; \\ *Penulis korespondensi.e-mail: ansharakhul@yahoo.co.id \\ (Diterima: 6 Desember 2018; Disetujui 19 Juni 2019)
}

\begin{abstract}
This study aims to determine the level of development and strategies for rural development based on industrial plants. This study uses primary and secondary data in the form of village potential data, supporting facilities, population numbers, accessibility, service facilities, institutions, disasters, and infectious diseases. Rural development based on industrial plants in Takalar District is spread in most rural areas. Industry with leading commodity of sugar cane is expected to be the spearhead of village development. However, based on BPS data, there was a decrease in sugar cane productivity during 2012-2016. The result of the analysis shows that the level of rural development based on industrial plants in North Polombangkeng district was higher than that South Polombangkeng district. It can be seen from the result of the scoring analysis which shows that two villages namely Palleko village and Massamaturu village, each weights 75 and 74, are located in North Polombangkeng district. This study recommends that in balancing the level of village development based on sugarcane plants, the local government and private sector should improve infrastructure and human resources as a whole.
\end{abstract}

Keywords: development, industry, sugarcane plants

\begin{abstract}
ABSTRAK
Penelitian ini bertujuan untuk mengetahui tingkat perkembangan dan strategi pengembangan perdesaan berbasis tanaman industri. Penelitian ini menggunakan data primer dan sekunder berupa data Potensi Desa, fasilitas penunjang, jumlah penduduk, aksesibilitas, fasilitas pelayanan jasajasa, kelembagaan, gangguan bencana, dan penyakit menular. Pengembangan perdesaan berbasis tanaman industri di Kabupaten Takalar tersebar di sebagian besar wilayah perdesaan. Industri dengan komoditas unggulan tanaman tebu diharapkan sebagai ujung tombak perkembangan desa. Namun berdasarkan data BPS, terjadi penurunan produktivitas tanaman tebu selama tahun 20122016. Dari hasil analisis diperoleh tingkat perkembangan perdesaan yang berbasis tanaman industri di Kecamatan Polombangkeng Utara lebih tinggi dibandingkan dengan di Kecamatan Polombangkeng Selatan. Hal tersebut dapat dilihat dari hasil analisis skoring yang menunjukkan bahwa dua desa yakni desa Palleko dan desa Massamaturu masing-masing memiliki bobot 75 dan 74 terletak di Kecamatan Polombangkeng Utara. Penelitian ini merekomendasikan agar dalam menyeimbangkan tingkat perkembangan desa berbasis tanaman tebu, pemerintah dan swasta dapat melakukan peningkatan infrastruktur dan sumber daya manusia secara menyeluruh.
\end{abstract}

Kata kunci: industri, perkembangan, tanaman tebu 


\section{PENDAHULUAN}

Pengembangan wilayah pada kawasan perdesaan adalah pembangunan antar desa berdasarkan prioritas pada pengembangan potensi dan/atau pemecahan masalah yang mengutamakan keterkaitan desa-kota dengan memperhatikan daya dukung lingkungan. (Muta'ali, 2015).

Pemahaman pembangunan wilayah yang holistik dan terpadu menjadi penting dan mendasar yang berkaitan dengan perdesaan maupun perkotaan agar terjadi sinergitas, sinkron dan terintegrasi terhadap perlakuan wilayah khususnya oleh pelaku pembangunan. (Anshar et al., 2019)

Proses industrialisasi sangat erat kaitannya dalam pembangunan khususnya pengembangan wilayah perdesaan berbasis komoditas pertanian. (Syahza \& Suarman, 2013). Industrialisasi pada hakekatnya suatu proses perubahan sosial ekonomi yang merupakan proses pembangunan masyarakat dalam peningkatan kualitas serta membangun potensi manusia Indonesia (Pramono, 2012). Dalam pandangan lain, pembangunan industri merupakan aktivitas yang berdaya guna dan berhasil guna dalam mendorong pada peningkatkan kesejahteraan masyarakat, dengan indikator tercapainya kualitas kehidupan yang lebih baik sehingga pembangunan industri tidak hanya dalam pencapaian kegiatan mandiri tetapi mempunyai tujuan pokok untuk peningkatan kesejahteraan masyarakat di wilayah sekitarnya (Ishak, 2014).

Undang-Undang Nomor 5 Tahun 1984 tentang Perindustrian mendeskripsikan perindustrian sebagai kegiatan ekonomi baik industri berupa barang maupun industri jasa yang mengolah bahan mentah, bahan baku, barang setengah jadi, dan/atau barang jadi menjadi barang dengan nilai yang lebih tinggi.

Agroindustri sebagai kegiatan dalam pemanfaatan hasil pertanian sebagai bahan baku atau mendesain dan menyediakan peralatan dan jasa banyak diminati oleh sebagian masyarakat desa karena eksistensinya sudah banyak berpengaruh pada peningkatan perekonomian masyarakat dan peningkatan perekonomian nasional. (Diartho, 2018). Agroindustri yang merambah ke wilayah perdesaan menimbulkan dampak diberbagai bidang seperti ekonomi, sosial, dan budaya. Dengan aktivitis berbasis komoditas wilayah perdesaan tersebut.

Wilayah Provinsi Sulawesi Selatan khususnya Kabupaten Takalar merupakan salah satu dari 23 Kabupaten/Kota yang terletak pada wilayah geografis dan lokasi yang cukup strategis dengan iklim yang tergolong iklim tropis menjadi hal yang menguntungkan bagi petani. Penduduknya rata-rata bermata pencaharian di sektor pertanian, terutama pertanian tanaman padi, jagung, dan perkebunan tebu. Rata-rata produktivitas tanaman padi mencapai 4.51 ton/ha. Sedangkan produksi tanaman perkebunan yang terkenal dan menjadi komoditas unggulan yaitu tanaman tebu, yang memiliki produksi pertanian sekitar 1,500 ton. Dokumen Rencana Tata Ruang Wilayah (RTRW) Kabupaten Takalar menegaskan bahwa sektor ekonomi yang memberikan nilai kontribusi besar terhadap perekonomian Kabupaten Takalar adalah sektor perkebunan ditunjang dengan adanya industri pengelolaan Pabrik Gula Takalar di Kecamatan Polombangkeng Utara. Tebu sebagai komoditas unggulan yang didukung dengan Pabrik Gula (PG) Takalar. Pabrik ini dikelola oleh Badan Usaha Milik Negara (BUMN) yang dikontrak oleh PTPN XIV (Persero) yang telah beroperasi sejak tahun 1982.

Pengembangan Perdesaan berbasis agroindustri di Kabupaten Takalar yang tersebar di sebagian besar wilayah perdesaan di dua kecamatan yakni Polombangkeng Utara dan Polombangkeng Selatan, baik industri rumah tangga, kecil sampai skala besar. Industri dengan komoditas unggulan tanaman perkebunan/industri (tebu) diharapkan sebagai ujung tombak perkembangan desa. Namun berdasarkan data BPS terjadi penurunan produktifitas tanaman tebu tahun 2012-2016.

Usaha tanaman industri belum begitu berkembang dimana usaha tanaman industri dapat meningkatkan pendapatan dan kesejahteraan bagi petani. 
Wilayah studi memiliki potensi yang strategis dalam pengembangan sektor pertanian khususnya tanaman industri yaitu tersedianya lahan yang luas dan cocok serta SDM petani yang beraktivitas di sektor ini dengan memperhatikan tipologi wilayah. (Maulana et al., 2011).

Berbagai permasalahan dan kendala selama ini banyak dihadapi petani yang berada di Kabupaten Takalar, baik menyangkut infrastruktur yang masih terbatas, kesulitan dalam permodalan, terbatasnya penguasaan teknologi baik dalam usaha tani maupun pengelolaan hasilnya, dan kesulitan dalam pemasaran produk yang dihasilkan. (Tayibnapis et al., 2018).

Hal demikian menyebabkan kegiatan perekonomian di sebagian besar daerah perdesaan belum berkembang sebagaimana yang diharapkan dan banyaknya kantongkantong kemiskinan di daerah perdesaan dan kecamatan pada wilayah studi masih berada pada angka kemiskinan tertinggi di Kabupaten Takalar.

Kabupaten Takalar dibagi sembilan Kecamatan dimana terdapat dua desa berbasis tanaman industri (tebu). Di lokasi studi terdapat satu industri besar di Kecamatan Polombangkeng Utara. Dalam hal penyerapan tenaga kerja sektor tanaman industri mempunyai peranan yang strategis. Pada tahun 2016, berdasarkan data BPS Kabupaten Takalar (2017) penduduk yang bekerja di industri yang berumur 15 tahun ke atas yang bekerja di sektor industri yakni sebanyak 1,025 orang $(6.53 \%)$ dari jumlah penduduk. Penyerapan Tenaga kerja yang tidak mementingkan masyarakat sekitar terkhusus pada sektor industri gula dapat menjadi faktor perkembangan dan kesejahteraan desa. Berdasarkan hal tersebut terdapat ketimpangan, dimana luas lahan tanaman industri yang luas, namun penyerapan tenaga kerja tidak seimbang. Tenaga kerja di sektor industri yang sangat sedikit menyerap penduduk di sekitar industri.
Di sisi lain sektor tanaman pangan, penyerapan tenaga kerja dari tahun ke tahun terus mengalami peningkatan namun mengalami penurunan produktivitas pada lima tahun terakhir (BPS Kabupaten Takalar, 2017).

Untuk mengatasi permasalahan tersebut di atas, maka upaya pengembangan komoditas tanaman industri di Kabupaten Takalar perlu disinkronkan dengan upaya peningkatan/ pengembangan agroindustri, pengembangan perdesaan serta pemberdayaan masyarakat tani (Astati et al., 2019). Dengan melihat hal tesebut, peneliti perlu melakukan penelitian dengan judul "Strategi Pengembangan Perdesaan Berbasis Tanaman Tebu di Kabupaten Takalar".

\section{METODOLOGI}

Lokasi penelitian ditentukan dengan pertimbangan masih banyaknya desa yang pengembangannya sangat lambat sehingga masih tertinggal dari desa atau kelurahan yang lainnya.

Berdasarkan pertimbangan tersebut, maka penelitian dilakukan di Kabupaten Takalar (untuk level makro) dan dua kecamatan sesuai basis perkembangan desa yang sudah ditetapkan (level mikro) secara sengaja (purposive) dengan pertimbangan data diperoleh bisa lebih representatif. Teknik analisis data melalui Analisis skoring. Pengukuran tingkat perkembangan desa dalam kajian ini berdasarkan pada hasil publikasi BPS melalui Data Potensi desa tahun 2018 di desa se-Kabupaten Takalar.

Berdasarkan pada definisi Kementerian Desa, Pembangunan Daerah Tertinggal, dan Transmigrasi Republik Indonesia (2018), daerah tertinggal adalah sebuah daerah yang perkembangannya berada pada titik di bawah angka rataan perkembangan nasional. Indikator penilaian dengan standar berdasarkan Departemen Pekerjaan Umum (PU). 


\section{a. Potensi Desa}

Salah satu variabel yang digunakan dalam menentukan tingkat perkembangan desa yakni potensi desa. Ada beberapa sub-variabel yang digunakan untuk mengetahui desa yang memiliki potensi yang baik dan berkembang, yang dapat dilihat pada Tabel 1 .

Tabel 1 Penilaian berdasarkan potensi desa

\begin{tabular}{|c|c|}
\hline Variabel/Kriteria & Penilaian \\
\hline \multicolumn{2}{|l|}{ a. Klasifikasi Desa } \\
\hline Swadaya & 1 \\
\hline Swakarya & 3 \\
\hline Swasembada & 5 \\
\hline \multicolumn{2}{|l|}{ b. Jumlah Dominan Rumah } \\
\hline Dibidang Pertanian & 1 \\
\hline Dibidang Industri dan Kerajinan & 5 \\
\hline Dibidang Perdagangan dan Jasa & 3 \\
\hline Dibidang Lainnya & 2 \\
\hline \multicolumn{2}{|l|}{ c. Pengelolaan Kegiatan (0-5) } \\
\hline Organisasi Pertanian/ Nelayan & 3 \\
\hline Badan Usaha/Perusahaan & 5 \\
\hline Tidak ada organisasi & 1 \\
\hline \multicolumn{2}{|l|}{ d. Jumlah pabrik ( 0-5 ) } \\
\hline$>5$ buah & 5 \\
\hline $2-4$ buah & 3 \\
\hline$<2$ buah & 1 \\
\hline \multicolumn{2}{|l|}{ e. Sektor Ekonomi Potensial (0-5) } \\
\hline $\begin{array}{l}\text { Sawah/Perkebunan/ Perikanan/ } \\
\text { Lahan kering }\end{array}$ & 1 \\
\hline Industri Kecil & 3 \\
\hline Industri Besar dan Sedang & 5 \\
\hline Perdagangan dan Jasa & 5 \\
\hline Lainnya & 2 \\
\hline Total Penilaian & 49 \\
\hline
\end{tabular}

\section{b. Fasilitas \\ untuk}

\section{Perkembangan Produksi dan Jasa}

Pada variabel ini terdapat empat sub variabel untuk mengetahui desa yang memiliki potensi baik yang dapat menunjang perkembangan produksi dan jasa, yaitu pasar, listrik, komunikasi, dan perkreditan [Tabel 2].
Tabel 2 Penilaian berdasarkan fasilitas penunjang perkembangan produksi dan jasa

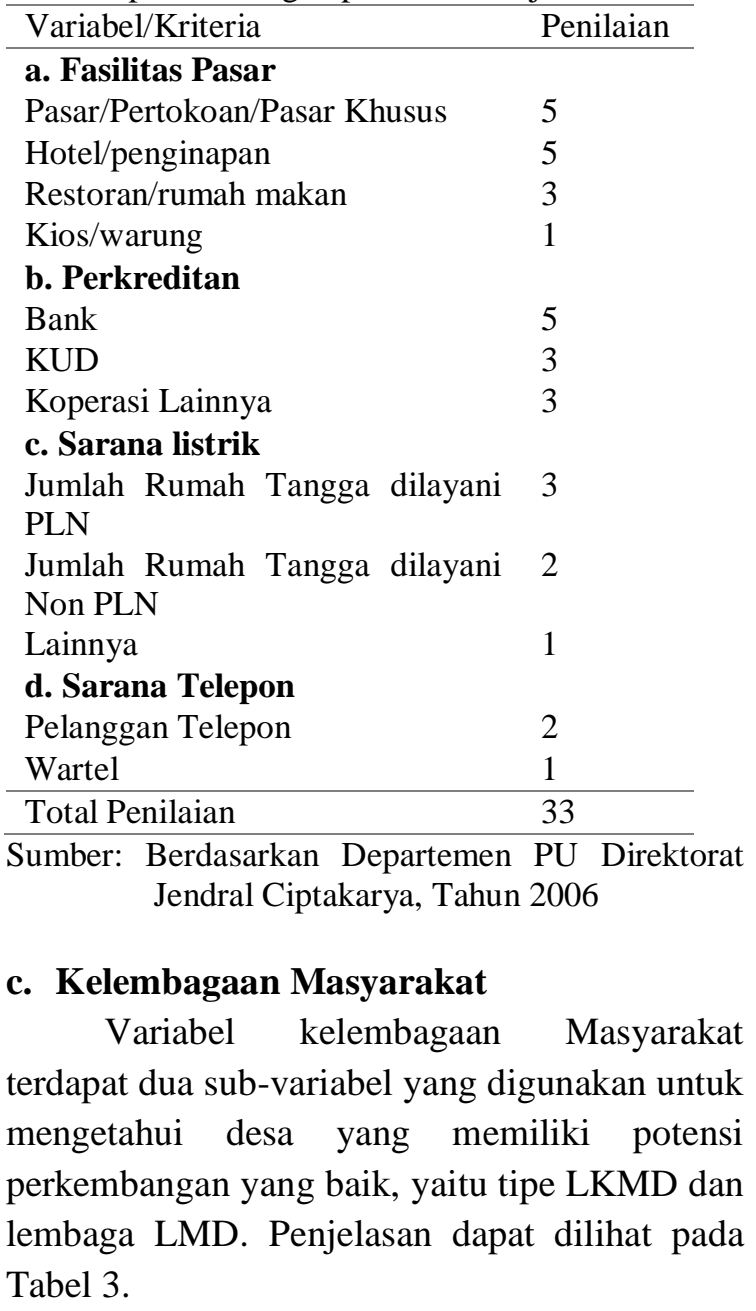

Tabel 3 Penilaian berdasarkan kelembagaan masyarakat

\begin{tabular}{ll}
\hline Variabel/Kriteria & Penilaian \\
\hline a. Tipe LKMD & \\
1. Tipe 1 & 1 \\
2. Tipe 2 & 2 \\
3. Tipe 3 & 3
\end{tabular}

\section{b. Badan Keswadayaan Masyarakat} (Ada/Tidak ada)

$\begin{array}{ll}\text { 1. Ada } & 3 \\ \text { 2. Tidak Ada } & 0 \\ \text { Total Penilaian } & 6\end{array}$

Sumber: Berdasarkan Departemen PU Direktorat Jendral Ciptakarya, Tahun 2006 


\section{d. Fasilitas untuk Pelayanan Jasa-jasa}

Variabel ini terdapat beberpa subvariabel yang digunakan untuk mengetahui desa yang memiliki tingkat perkembangannya lebih tinggi. Penjelasan dapat dilihat pada Tabel 4.

Tabel 4 Penilaian berdasarkan fasilitas untuk pelayanan jasa-jasa

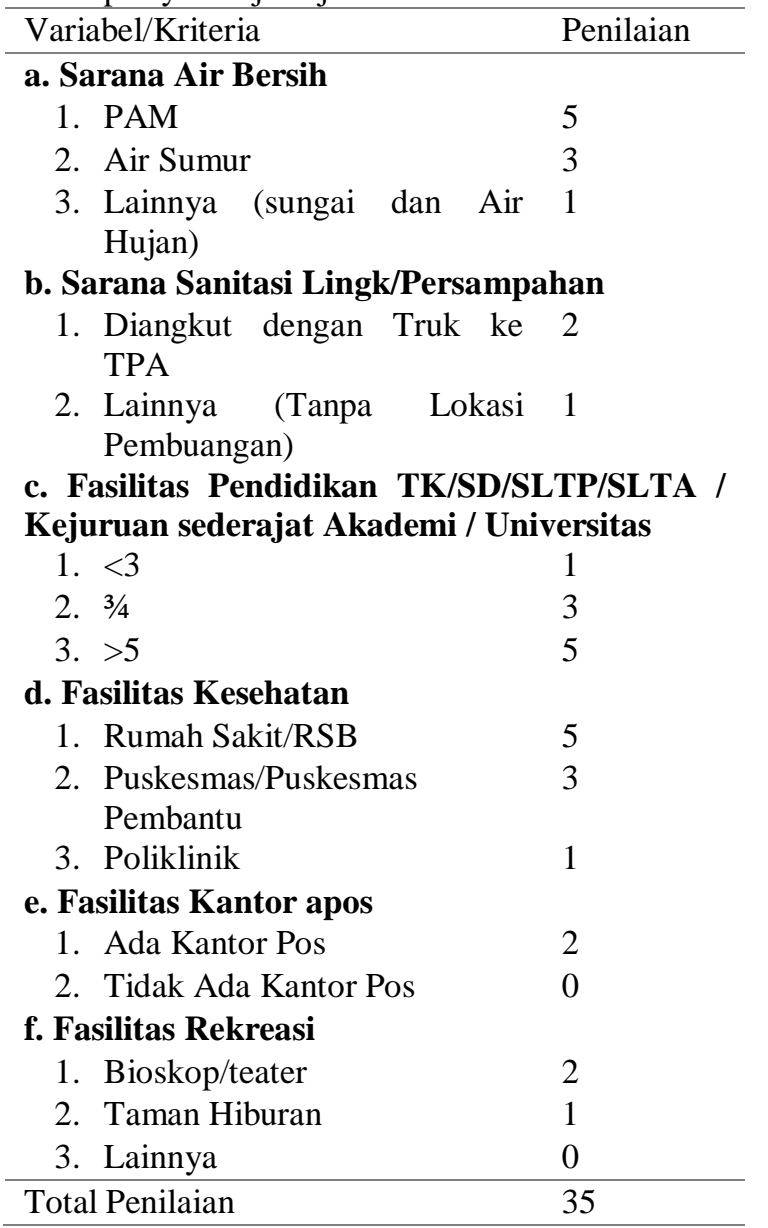

Sumber: Berdasarkan Departemen PU Direktorat Jendral Ciptakarya, Tahun 2006

\section{e. Jumlah Penduduk}

Variabel jumlah penduduk hanya satu sub variabel yang digunakan, yaitu kepadatan penduduk [Tabel 5].

Tabel 5 Penilaian berdasarkan kelembagaan masyarakat

\begin{tabular}{ll}
\hline Variabel/Kriteria & Penilaian \\
\hline a. Kepadatan penduduk & \\
1. $>50$ jiwa per $\mathrm{km}^{2}$ & 5 \\
2. $25-49$ jiwa per $\mathrm{km}^{2}$ & 3 \\
3. $<25$ jiwa per km & 1 \\
\hline Total Penilaian & 9
\end{tabular}

Sumber: Berdasarkan Departemen PU Direktorat Jendral Ciptakarya, Tahun 2006

\section{f. Aksesibilitas}

Variabel aksesibilitas terdiri dari empat sub variabel yang digunakan, yakni kualitas jalan, sarana angkutan, dan moda angkutan. Untuk hal tersebut mengenai variabel dan indikator dalam penelitian ini, dapat dilihat pada Tabel 6.

Tabel 6 Penilaian berdasarkan aksesibilitas

\begin{tabular}{ll}
\hline Variabel/Kriteria & Penilaian \\
\hline a. Kualitas Jalan (0-5) & \\
1. Aspal & 5 \\
2. Diperkeras & 3 \\
3. Tanah & 1
\end{tabular}

b. Sarana Angkutan

$\begin{array}{ll}\text { 1. Terminal } & 5 \\ \text { 2. Lainnya } & 0 \\ \text { Moda Angkutan (0-5) } & \\ \text { 1. Kendaraan bermotor } & 5 \\ \text { roda 4/3 } & \\ \text { 2. Sepeda motor } & 3 \\ \text { 3. Delman/dokar/gerobak/ } & 2 \\ \text { pedati } & \\ \text { 4. Lainnya } & 1\end{array}$

d. Jarak Desa ke Ibukota Kabupaten (0-5)

\begin{tabular}{ll} 
1. $>25 \mathrm{~km}$ & 1 \\
2. $10-25 \mathrm{~km}$ & 3 \\
3. $<10 \mathrm{~km}$ & 5 \\
\hline Total Penilaian & 34
\end{tabular}

Sumber: Berdasarkan Departemen PU Direktorat Jendral Ciptakarya, Tahun 2006

\section{g. Ganguan Bencana Alam dan Penyakit Menular}

Variabel ini hanya terdiri dari dua sub variabel yang digunakan, yaitu bencana alam dan epidemi penyakit menular [Tabel 7].

Tabel 7 Penilaian berdasarkan gangguan bencana alam dan penyakit menular

\begin{tabular}{ll}
\hline Variabel/Kriteria & Penilaian \\
\hline a. Bencana Alam & \\
1. Kekeringan & 5 \\
2. Banjir & 3 \\
3. Gempa bumi & 2 \\
4. Gunung meletus & 1 \\
5. Lainnya & 0
\end{tabular}

b. Epidemi penyakit menular
1. Muntaber
5
2. Demam berdarah 3
3. Lainnya. 1

Total Penilaian 19

Sumber: Berdasarkan Departemen PU Direktorat Jendral Ciptakarya, Tahun 2006 
Interpretasi penilaian untuk mengetahui tingkat perkembangan desa berdasarkan total 7 (tujuh) variabel di atas dilakukan dengan melakukan penskoran terhadap 3 kategori berdasarkan distribusi data sebagai berikut,

a. Nilai 74-100 sebagai desa/kelurahan tingkat perkembangannya tinggi.

b. Nilai $45-73$ sebagai desa/kelurahan tingkat perkembangannya sedang.

c. Nilai <45 sebagai desa/kelurahan tingkat perkembangannya rendah.

Dari skoring nilai sesuai dengan variabel dengan memperhatikan indikator masingmasing akan menghasilkan kategori dan tolok ukur perkembangan desa. Hasil skoring tersebut dideskripsikan sehingga mendapatkan informasi tingkat perkembangan perdesaan berbasis tanaman industri tebu.
Untuk mendapatkan alternatif strategi pengembangan perdesaan dilanjutkan dengan Analisis SWOT yang merupakan metode perencanaan strategis yang digunakan untuk mengevaluasi kekuatan (strengths), kelemahan (weaknesses), peluang (opportunities) dan ancaman (threats).

\section{HASIL DAN PEMBAHASAN}

\section{Analisis tingkat perkembangan perdesaan berbasis tanaman industri}

Secara spasial penyebaran tanaman industri tebu terkonsentrasi di bagian timur Kabupaten Takalar, yakni di Kecamatan Polombangkeng Utara dan Polombangkeng Selatan.

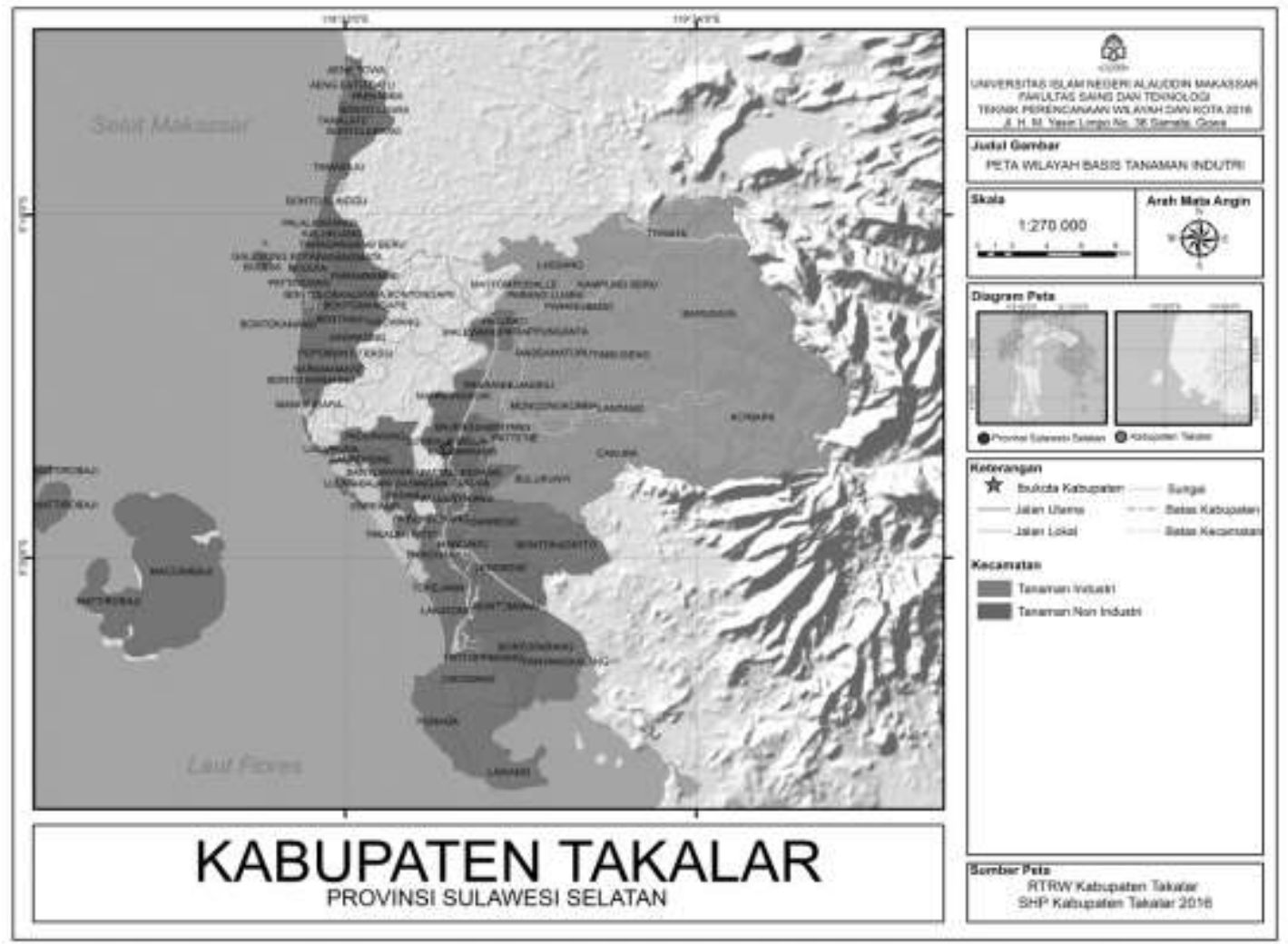

Gambar 1 Peta wilayah kawasan tanaman industri Sumber: RTRW Kabupaten Takalar, 2016

Hasil Analisis skoring ini menunjukkan bahwa desa yang berbasis tanaman industri tebu terdapat dua kecamatan yakni Kecamatan Polombangkeng Utara dan Polombangkeng Selatan. Hasil analisis menunjukkan bahwa desa-desa di Kecamatan Polombangkeng Utara perkembangannya lebih tinggi dibandingkan dengan desa-desa di Kecamatan Polombangkeng Selatan. Terdapat 23 desa yang berbasis tanaman industri tebu di Kabupaten 
Takalar, masing-masing 8 desa di Kecamatan Polombangkeng Selatan dan 15 desa di Polombangkeng Utara.

\section{Analisis strategi pengembangan perdesaan berbasis tanaman industri Tebu}

Metode perencanaan melalui analisis SWOT (Strength, Weakness, Opportunity, and Threat) untuk mengevaluasi dalam menyusun strategi pengembangan perdesaan berbasis tanaman industri tebu, dilakukan dengan faktorfaktor analisis sebagai berikut.

a. Kekuatan (S):

1. Aksesibilitas tiap desa sangat strategis berdekatan dengan Ibukota Kabupaten.

2. Kondisi lahan yang $80 \%$ datar.

3. Kebijakan pemerintah dalam bentuk penetapan sebagai kawasan strategis provinsi penghasil gula.

4. Kelembagaan tiap desa yang proaktif dalam bidang pertanian.

b. Kelemahan (W):

1. Produktivitas tanaman pangan dan industri mengalami penurunan.

2. Kondisi pabrik yang sudah tua yang mempengaruhi aktivitas industri.

c. Peluang $(\mathrm{O})$ :

1. Menjadi kawasan andalan penghasil tanaman pangan dan tanaman industri.

2. Pembukaan lapangan kerja yang lebih banyak akan mengurangi pengangguran.

3. Peningkatan pengelolaan kawasan industri yang akan berpengaruh dari aspek perekonomian masyarakat.

d. Ancaman (T):

1. Tingkat pengalihan fungsi lahan pertanian maupun perkebunan.

2. Masuknya pekerja dari luar yang mendominasi industri tebu.

3. Peningkatan kebutuhan pelayanan sarana dan prasarana masyarakat dari tahun ke tahun.

\section{Analisis Faktor Strategi Internal (IFAS) dan Analisis Faktor Strategi Eksternal (EFAS)}

Evaluasi strategis dari faktor-faktor internal dan eksternal diidentifikasi dan disusun untuk merumuskan strategi tersebut dalam kerangka SWOT. Analisis yang diperoleh adalah sebagai berikut.

a. Strategi SO:

1. Memanfaatkan Aksesibilitas kawasan sebagai pendukung utama kawasan andalan tanaman pangan maupun industri tebu.

2. Pengembangan kawasan lahan sebagai pendukung perekonomian masyarakat.

3. Peningkatan sinergitas antara pemerintah dan petani tebu serta pihak investor/swasta dalam pengembangan perdesaan berbasis tanaman industri tebu.

4. Melibatkan semua kalangan baik pemerintah, swasta, dan masyarakat dalam pengembangan desa/kelurahan dari perencanaan hingga proses pembangunan.

b. Strategi ST:

1. Mengadakan peraturan daerah/kawasan dan perencanaan mengenai fungsi lahan pengan dan industri tebu.

2. Meningkatkan peran pemuda/masyarakat melalui peningkatan SDM dan pemberdayaan dalam upaya siap menjadi tenaga kerja yang kompeten.

3. Meningkatkan pelayanan sarana dan prasarana permukiman dalam memenuhi kebutuhan masyarakat dengan memanfaatkan kelembagaan masyarakat.

c. Strategi WO:

1. Pembuatan program/pelatihan rutin kepada petani dan pekerja industri dalam pengembangan produktivitas tanaman pangan maupun tanaman indutri.

2. Melakukan pembaharuan pabrik untuk menghindari kerusakan pada mesin sehingga tidak terpengaruh terhadap aktivitas pekerja dan hasil industri.

3. Pengelolaan kawasan perdesaan berbasis tanaman industri dan pangan dalam meningkatkan kualitas kehidupan masyarakat.

d. Strategi WT:

1. Sosialisasi pentingnya pengaturan dan perencanaan kawasan yang akan berdampak terhadap produktivitas lahan. 
2. Peningkatan kualitas pelayanan saranaprasarana tiap desa/kelurahan di Kabupaten Takalar.

3. Pemberdayaan masyarakat pekerja di kawasan industri dan petani dalam pengembangan SDM untuk pengembangan desa/kelurahan.

Berdasarkan isu-isu yang berkembang di wilayah penelitian, yang paling berpengaruh sebagai berikut.

Tabel 8 Pembobotan SWOT ditinjau dari faktor internal

\begin{tabular}{|c|c|c|c|c|}
\hline No & Faktor & Bobot & Rating & $\mathrm{B} \times \mathrm{R}$ \\
\hline \multirow[t]{6}{*}{1} & Kekuatan & & & \\
\hline & $\begin{array}{l}\text { Aksesibilitas tiap desa sangat strategis } \\
\text { berdekatan dengan Ibukota Kabupaten. }\end{array}$ & 0.1 & 2 & 0.2 \\
\hline & Kondisi lahan yang $80 \%$ datar. & 0.1 & 2 & 0.2 \\
\hline & $\begin{array}{l}\text { Kebijakan pemerintah dalam bentuk } \\
\text { penetapan sebagai kawasan strategis provinsi } \\
\text { penghasil gula. }\end{array}$ & 0.2 & 4 & 0.8 \\
\hline & $\begin{array}{l}\text { Kelembagaan tiap desa yang proaktif dalam } \\
\text { bidang pertanian. }\end{array}$ & 0.1 & 3 & 0.3 \\
\hline & Jumlah & 0.5 & 9 & 1.7 \\
\hline \multirow[t]{5}{*}{2} & Kelemahan & & & \\
\hline & $\begin{array}{l}\text { Produktivitas tanaman pangan dan industri } \\
\text { mengalami penurunan. }\end{array}$ & 0.3 & 3 & 0.9 \\
\hline & $\begin{array}{l}\text { Kondisi pabrik yang sudah tua mempengaruhi } \\
\text { aktivitas industri. }\end{array}$ & 0.2 & 2 & 0.4 \\
\hline & Jumlah & 0.5 & 5 & 1.3 \\
\hline & Total & & 14 & 3.0 \\
\hline
\end{tabular}

Sumber: Hasil analisis, 2017

Tabel 9 Pembobotan analisis SWOT ditinjau dari faktor eksternal

\begin{tabular}{|c|c|c|}
\hline NoFaktor & Bobot Rating & \multirow[t]{2}{*}{$\mathrm{B} \times \mathrm{R}$} \\
\hline 1 Peluang & & \\
\hline $\begin{array}{l}\text { Menjadi kawasan andalan penghasil tanaman pangan dan } \\
\text { tanaman industri tebu }\end{array}$ & 0.3 & 0.9 \\
\hline $\begin{array}{l}\text { Pembukaan lapangan kerja yang lebih banyak akan } \\
\text { mengurangi pengangguran. }\end{array}$ & 0.1 & 0.3 \\
\hline $\begin{array}{l}\text { Peningkatan pengelolaan kawasan industri yang akan } \\
\text { berpengaruh dari aspek perekonomian masyarakat. }\end{array}$ & 0.1 & 0.2 \\
\hline Jumlah & 0.5 & 1.4 \\
\hline \multicolumn{3}{|l|}{2 Ancaman } \\
\hline $\begin{array}{l}\text { Tingkat pengalihan fungsi lahan yang pertanian maupun } \\
\text { perkebunan. }\end{array}$ & 0.2 & 0.8 \\
\hline Masuknya pekerja dari luar yang mendominasi industri tebu & 0.2 & 0.6 \\
\hline $\begin{array}{l}\text { Peningkatan kebutuhan pelayanan sarana dan prasarana } \\
\text { masyarakat dari tahun ke tahun. }\end{array}$ & 0.1 & 0.3 \\
\hline Jumlah & 0.5 & 1.7 \\
\hline Jumlah & 17 & 3.1 \\
\hline Total & 31 & 6.1 \\
\hline
\end{tabular}

Sumber: Hasil analisis, 2017

Faktor Internal: Kekuatan - Kelemahan $=1.7-1.3=0.4(+)$

Faktor Eksternal: Peluang - Ancaman $=1.4-1.7=-0.3(-)$ 


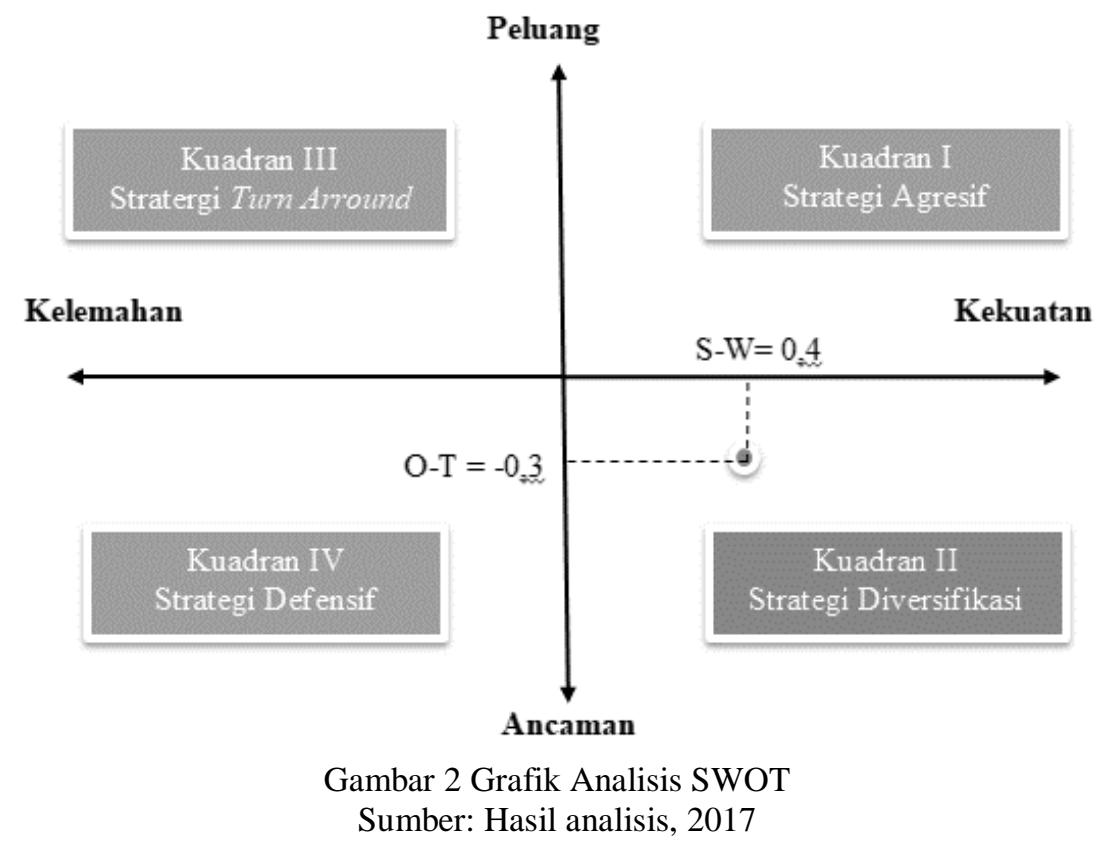

Dari grafik analisis SWOT di atas menunjukkan bahwa pengembangan perdesaan berbasis tanaman industri tebu berada pada posisi kuadran II (positif, Negatif). Alternatif rekomendasi strategi yang dihasilkan adalah Strategi S-T. Hasil analisis SWOT tersebut di atas digunakan Strategi (ST) yang dapat dijabarkan sebagai berikut: (1) Mengadakan peraturan daerah/kawasan dan perencanaan mengenai fungsi lahan pangan dan industri tebu; (2) Meningkatkan peran pemuda/masyarakat melalui peningkatan SDM dan pemberdayaan dalam upaya siap menjadi tenaga kerja yang kompeten; (3) Meningkatkan pelayanan sarana dan prasarana permukiman dalam memenuhi kebutuhan masyarakat dengan memanfaatkan kelembagaan masyarakat.

\section{KESIMPULAN}

Wilayah Kecamatan yang tingkat perkembangannya tinggi adalah Polombangkeng Utara pada Desa Pallekko sebagai desa berbasis tanaman industri tebu yang mempunyai skor tertinggi dan Desa Massamaturu.

Desa-desa yang berada di Kecamatan Polombangkeng Utara tingkat perkembangannnya lebih tinggi. Hal ini diperkuat dengan letak industri gula yang memang berada di Kecamatan Polombangkeng Utara, sebagai penunjang ekonomi masyarakat.
Strategi yang dapat dilakukan dalam upaya pengembangan perdesaan berbasis tanaman industri tebu yakni; (1) Mengadakan peraturan daerah/kawasan dan perencanaan mengenai fungsi industri tebu; Meningkatkan peran pemuda/masyarakat melalui peningkatan SDM dan pemberdayaan dalam upaya siap menjadi tenaga kerja yang kompeten; (3) Meningkatkan pelayanan sarana dan prasarana permukiman dalam memenuhi kebutuhan masyarakat dengan memanfaatkan kelembagaan masyarakat.

\section{DAFTAR PUSTAKA}

Anshar, M., Astati, \& Wahida, N. (2019). The potential for rural resources development, specifically livestock commodities based on Geographic Information System (GIS) in Patukku Village, Bontocani District, Bone Regency. IOP Conf. Series: Earth and Environmental Science, 247, 1-9.

Astati, Paly, M. B., Suarda, A., Asgaf, K., Anshar, M., Mursidin, Rusny, \& Arfah. (2019). Empowerment and increasing the scale of beef cattle in Bonto Manai Village Bisappu District Bantaeng Regency. IOP Conf. Series: Earth and Environmental Science, 247, 1-8. 
BPS Kabupaten Takalar. (2017). Kabupaten Takalar dalam Angka 2016. Takalar: Badan Pusat Statistik.

Departemen Pekerjaan Umum Direktorat Jendral Ciptakarya. (2006). Pengembangan Permukiman.

Diartho, H. C. (2018). Pengembangan Wilayah Perdesaan Berbasis Pada Potensi Sumber Daya Alam di Kabupaten Bondowoso. EKONOMIKAWAN: Jurnal Ilmu Ekonomi dan Studi Pembangunan, 18 (2), 102-122.

Pramono, R. W. D. (2018). Pengaruh Fluktuasi Industrialisasi Terhadap Kapabilitas Masyarakat Pedesaan di Magelang. Jurnal Pembangunan Wilayah dan Kota, 14 (2), 95-107.

Ishak, A. F. (2014). Pengaruh Pertumbuhan Industri Terhadap Kesejahteraan Masyarkat di Provinsi Kalimantan Timur. Jurnal Ekonomi dan Bisnis, 24 (1), 1-6.

Maulana, M. \& Yana, E. P. S. (2011). Penetapan Tipologi Wilayah Sebagai Kriteria Alternatif Pemekaran Kecamatan (Studi Kasus di Kabupaten Mesuji). Jurnal Ilmiah Administrasi Publik dan Pembangunan "Administratio", 2 (2).

Muta'ali, L. (2012). Daya Dukung Lingkungan untuk Perencanaan Pengembangan Wilayah. Yogyakarta: Badan Penerbit Fakultas Geografi (BPFG) Universitas Gadjah Mada.

Syahza, A. S. (2013). Strategi Pengembangan Daerah Tertinggal dalam Upaya Percepatan Pembangunan Ekonomi Pedesaan. Jurnal Ekonomi Pembangunan, 14 (1), 26-130.

Tayibnapis, A. Z., Sundari, M. S., \& Wuryaningsih, L. E. (2018). Meningkatkan Daya Saing Pabrik Gula di Indonesia Era Masyarakat Ekonomi Asean. Jurnal Riset Ekonomi dan Manajemen, 16 (2), 225-236. 